\title{
Endoscopic and Microsurgical Approaches to the Cavernous Sinus - Anatomical Review
}

\section{Abordagem endoscópica e microcirúrgica do seio cavernoso - revisão da anatomia}

\author{
Flavio Ramalho Romero ${ }^{1}$ Daphyne Ramires ${ }^{1}$ Luigi Carrara Cristiano ${ }^{1}$ Marcos Paulo Silva ${ }^{1}$ \\ Rodolfo Brum Vieira ${ }^{1}$ \\ ${ }^{1}$ Faculdade de Medicina, Universidade Estadual Paulista Julio de \\ Mesquita Filho, Botucatu, São Paulo, Brazil \\ Address for correspondence Flavio Ramalho Romero, MD, MSc, PhD, \\ Universidade Estadual Paulista Julio de Mesquita Filho, Faculdade de \\ Medicina, Botucatu, São Paulo, Brazil (e-mail: frromero@ig.com.br).
}

Arq Bras Neurocir 2017;36:160-166.

\begin{abstract}
Keywords

- cavernous sinus

- endoscopic endonasal approach

- transsphenoidal surgery

- transpterygoid approach

- microsurgical cavernous sinus

\section{Resumo}

Palavras-chave

- seio cavernoso

- acesso endoscópico endonasal

- cirurgia transesfenoidal

- acesso transesfenoidal

- microcirurgia do seio cavernoso

Cavernous sinus surgery has always represented a surgical challenge due to the great importance of the surrounding anatomical structures and to the high morbidity associated to it. Although the anatomy of this region has been extensively described, controversy remains related to the best treatment and approaches for different kinds of lesions. In this article, a literature review was performed on the surgical anatomy and approaches to the cavernous sinus.

A cirurgia da região do seio cavernoso sempre representou um desafio devido à grande importância das estruturas anatômicas e às altas taxas de morbidade associadas. Embora a anatomia da região tenha sido extensivamente descrita, permanece controverso o melhor tratamento e o acesso para diferentes tipos de lesão que acometem a região. Neste artigo foi realizada uma revisão de literatura focando a anatomia cirúrgica e os acessos à região do seio cavernoso.
\end{abstract}

\section{Introduction}

Cavernous sinus surgery has always represented a surgical challenge due to the great importance of the surrounding received

March 27, 2017

accepted

May 31, 2017

published online

July 12,2017 anatomical structures and to the high morbidity associated to it. $^{1,2}$ The pathological findings of the cavernous sinus region are diverse and include intrinsic and extrinsic lesions, such as vascular and neoplastic lesions, and inflammatory diseases,
Copyright $\odot 2017$ by Thieme Revinter

Publicações Ltda, Rio de Janeiro, Brazil
License terms

(c) (i) $\ominus$ (\$) 
with several different approaches described to deal with lesions in and around this region. ${ }^{1,2}$ The aims of the surgery are to confirm cavernous sinus invasion, to reach a histological diagnosis, and to remove the tumor as radically as possible.,

Although the anatomy of this region has been extensively described, the best approach to cavernous sinus lesions is controversial. In this article, a literature review was performed using the main databases available (Embase, PubMed/MEDLINE, and Scielo) on surgical anatomy of the cavernous sinus focusing on the advantages and disadvantages of the endoscopic and microsurgical techniques. Some examples of cases are also presented.

\section{Anatomical Review of the Cavernous Sinus}

The cavernous sinus is a venous structure in the middle cranial base resting on the intracranial surface of the sphenoid and temporal bones, surrounded by dural walls, which contains neurovascular structures and face the sella turcica, with the pituitary gland on one side, and the temporal lobe on the other side. Defined as a dural envelope, it contains the third, fourth, fifth and sixth cranial nerves and the cavernous carotid artery ${ }^{1,2}$, but it is also the site of venous confluence that receives the terminal end of multiple veins from the orbit, the sylvian fissure, and the anterior and middle fossae. The cavernous sinus has free communication with the basilar, superior and inferior petrosal sinuses, and with the intercavernous sinuses. ${ }^{1-7}$

The cavernous sinus is located on the intracranial surface of the sphenoid and temporal bones (-Fig. 1). The anterior edge of the cavernous sinus extends downward from the lower surface of the anterior clinoid process along the anterior edge of the carotid sulcus and the posterior edge of the optic strut and superior orbital fissure. The posterior edge extends from the posterior clinoid process above to the junction of the petrous apex with the body of the sphenoid bone below. After defining the anterior and posterior limits, the upper and lower limits of the cavernous sinus are defined by lines extending from the upper and lower ends of the anterior and posterior edges. The inferior limit extends backward from just below the inferior edge of the superior orbital fissure and lower edge of the carotid sulcus, passes along the lateral edge of the intracranial end of the carotid canal, and ends at the superior end of the petroclival fissure. The superior limit extends from the lower surface of the base of the anterior clinoid process along the lateral margin of the sella to the posterior clinoid process. ${ }^{1-7}$

The posterior part of the lower edge of the sinus is located above the junction of the petrous apex and the body of the sphenoid bone at the upper end of the petroclival fissure, and the posterior edge of the medial wall rests against the lateral edge of the dorsum sellae. ${ }^{1-4}$ The cavernous sinus extends downward and laterally from the lateral margin of the sella, across the sphenoid body to the junction of the body and greater sphenoid wing of the sphenoid, but does not extend laterally to include the margins of the foramina ovale, rotundum, or spinosum, although venous channels coursing through and around these foramina empty into the sinus and are part of the pericavernous venous plexus. ${ }^{1-6}$
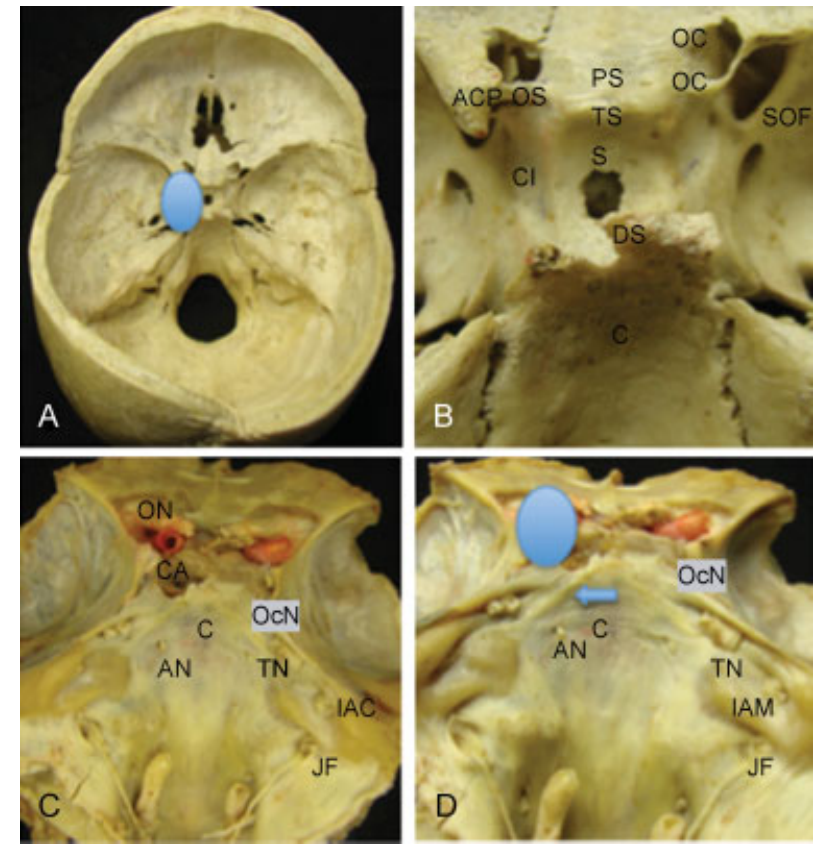

Fig. 1 (A and B) Osseous relationship in the central base of the skull; (C and D) dural and cranial nerve relationships in the base of the skull. The blue circle shows the position of the cavernous sinus, and the blue arrow indicates the Grubber ligament. Abbreviations: ACP, anterior clinoid process; AN, abducens nerve; $\mathrm{C}$, clivus; $\mathrm{CA}$, carotid artery; $\mathrm{Cl}$, carotid impression; DS, dorsum sellae; IAC, internal acoustic channel; IAM, internal acustic meatus; JF, jugular foramen; OC, optic channel; OcN, oculomotor nerve; ON, optic nerve; OS, optic strut; PS, planum sphenoidale; S, sella; SOF, superior orbital fissure; TN, trochlear nerve; TS, tuberculum sphenoidale.

The cavernous sinus has four walls: lateral and medial walls, a roof, and posterior walls. The roof faces the basal cisterns; the lateral wall faces the temporal lobe; the medial wall faces the sella turcica, pituitary gland, and sphenoid bone; and the posterior wall faces the posterior cranial fossa. The medial and lateral walls join inferiorly at the level of the superior margin of the second division of the trigeminal nerve (maxillary nerve), and the narrow anterior edge borders the superior orbital fissure. ${ }^{1-7}$

The nerves related to the cavernous sinus are the oculomotor, trochlear, ophthalmic, and abducens nerves, and the sympathetic plexus around the intracavernous carotid artery (-Fig. 2). The nerves in the sinus wall or sinus are, from superior to inferior, the third cranial nerve followed by the trochlear, ophthalmic, and abducens nerves. The oculomotor, trochlear, and ophthalmic nerves course along the inner part of the lateral sinus wall. The abducens nerve and the sympathetic plexus around the intracavernous carotid artery are the only nerves that have a purely intracavernous course. ${ }^{1-10}$

The oculomotor nerve courses along the lower edge of the anterior clinoid process to enter the superior orbital fissure. The trochlear nerve enters the roof of the sinus posterolateral to the third nerve and courses below the oculomotor nerve in the posterior part of the lateral wall. The ophthalmic nerve (the first and smallest trigeminal division) is embedded within the inner layer of the lateral wall of the cavernous sinus together with the oculomotor and trochlear nerves. 

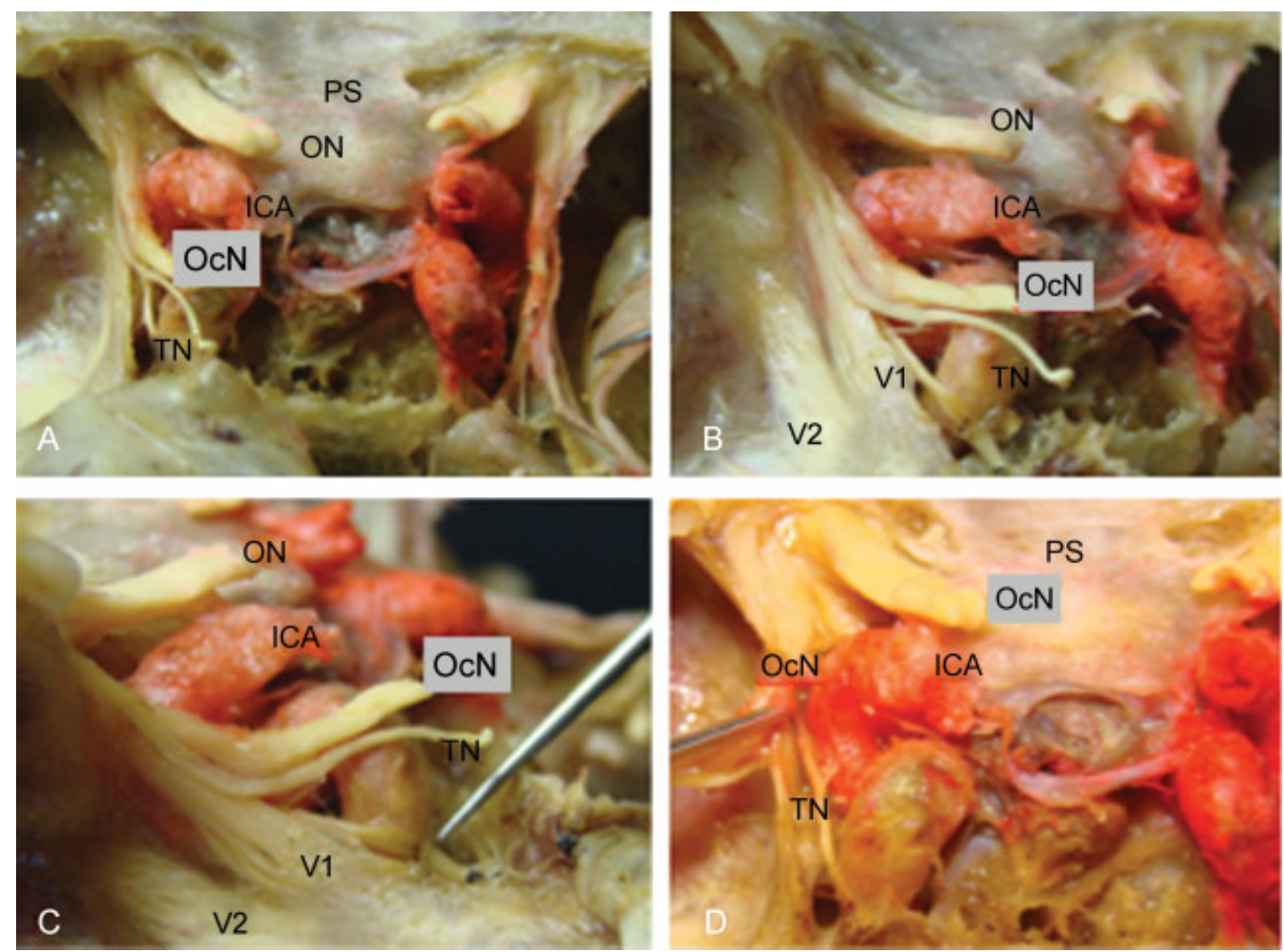

Fig. 2 Cavernous sinus structures after dural removal, in posteroanterior view (A); lateral view (B); oblique view (C); and anterior view (D). Abbreviations: ICA, internal carotid artery; OcN, oculomotor nerve; ON, optic nerve; PS, planum sphenoidale; TN, trochlear nerve; V1, ophthalmic portion of the trigeminal nerve; $\mathrm{V} 2$, mandibular portion of the trigeminal nerve.

The maxillary nerve (the second trigeminal division) courses below and does not belong to the lateral wall of the cavernous sinus. The cavernous sinus ends just above the superior margin of the maxillary nerve. ${ }^{1-3,7-10}$ The abducens nerve and the sympathetic plexus around the intracavernous carotid artery are the only nerves that have a purely intracavernous course ( - Fig. 2$) \cdot{ }^{7-10}$

The intracavernous carotid artery has five parts and two main branches. The five divisions are the posterior vertical segment, the posterior bend, the horizontal segment, the anterior bend, and the anterior vertical segment. The first branch, the meningohypophyseal trunk, arises from the posterior bend originating from the posterior bend of the intracavernous carotid artery and has three divisions: the dorsal meningeal artery, the inferior hypophyseal artery and the tentorial artery (artery of Bernasconi-Cassinari). The second branch, the inferolateral trunk, also called the artery of the inferior cavernous sinus, arises from the horizontal segment and nearly always passes above the abducens nerve and then downward between the abducens and ophthalmic nerves to supply the dura of the inferolateral wall of the cavernous sinus and adjacent area around the foramen rotundum and ovale. ${ }^{1-4}$

\section{Microsurgical Approaches to the Cavernous Sinus}

Parkinson, Dolenc and other neurosurgeons have described approaches to the cavernous sinus in published papers with few patients because of the risks and difficulty. ${ }^{8,11}$ This lack of information was largely a result of the inability in the premicrosurgical era to effectively address the extreme risks of significant hemorrhage and damage to the cranial nerves in the region. The modern era of microscopic neurosurgery has enabled expanded capabilities in surgical technique and has fostered the work of several neurosurgeons who have made great strides in effectively approaching this region with reduced morbidity. ${ }^{8-11}$ Moreover, new forms of therapy such as radiosurgery have been used, despite the controversial results. ${ }^{12}$

The indications for the surgical treatment of neoplastic lesions arising in or involving the cavernous sinus are controversial. . $^{811,12}$ The presence of a mass in the cavernous sinus, of course, does not itself constitute an absolute indication for a direct operation. Many variables must be taken into account, including the age and medical condition of the patient, the imaging characteristics, the adjacent structures involved, the time course of the process, and the functional severity of the symptoms. ${ }^{12-14}$

Very important to the surgeon's understanding of the relevant surgical anatomy of the cavernous sinus is a thorough working knowledge of the multiple triangular entry corridors into the region. Surgical facility with cavernous sinus lesions requires intimate knowledge of the entry spaces into the cavernous sinus to minimize morbidity. Some middle fossae triangles were described as possible entry corridors to the cavernous sinus ( - Fig. 3). ${ }^{1,2,11,12,14,15}$

The anterior triangle is exposed by removing the anterior clinoid process, either intradurally or extradurally. The boundaries of the triangle are the extradural optic nerve, the fibrous 

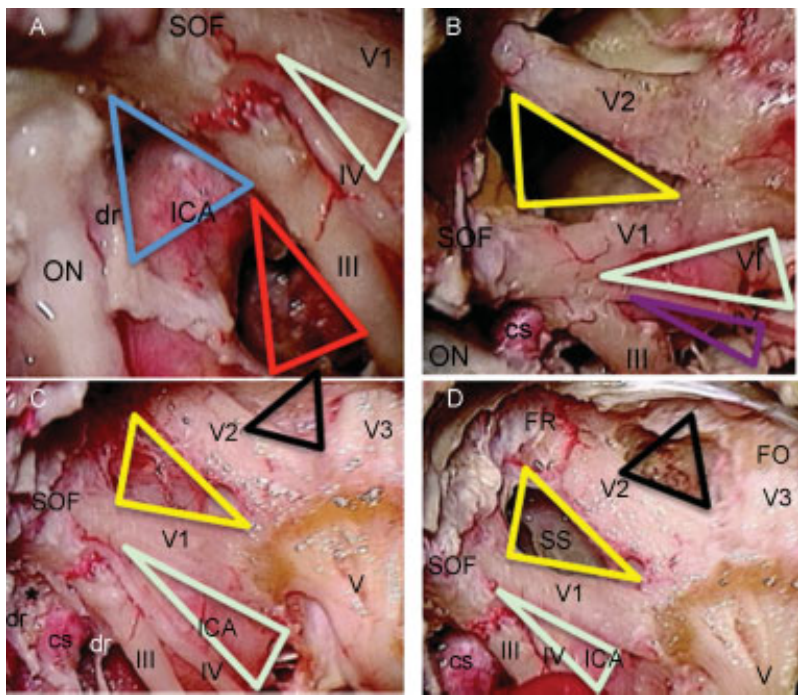

Fig. 3 Microsurgical cavernous sinus view and its relationships. Abbreviations: $\mathrm{CS}$, cavernous sinus; dr, dural ring; $\mathrm{FR}$, foramen rotundum; $\mathrm{FO}$, foramen ovale; ICA, internal carotid artery; ON, optic nerve; SOF, superior orbital fissure; SS, sphenoidal sinus; $\mathrm{V}$, trigeminal nerve; $\mathrm{V} 1$, ophthalmic portion of the trigeminal nerve; $\mathrm{V} 2$, mandibular portion of the trigeminal nerve; V3;.III, oculomotor nerve; IV, troclear nerve, VI, abducens nerve. Notes: ${ }^{*}$ optic strut; blue - anterior triangle; red - medial triangle; green lateral triangle; purple - posteroinferior triangle; yellow - anterolateral triangle; black - far lateral triangle.

dural ring, and the medial wall of the superior orbital fissure. The intradural carotid artery, the posterior clinoid process, the porus oculomotorius, and the siphon angle of the carotid artery delimit the medial triangle. This space is also critical in terms of exposure for most intracavernous tumors. The superior triangle is bounded by the oculomotor and trochlear nerves medially and laterally, and by the dura along the petrous ridge posteriorly. This triangle is the entry corridor used to locate the meningohypophyseal trunk. ${ }^{16-19}$

The lateral triangle is a very narrow space that is delimited by the trochlear nerve medially and by the ophthalmic division of the trigeminal nerve laterally, and the dura of the petrous ridge forms the posterior margin. ${ }^{16,17}$ The posterolateral triangle, first described by Glasscock in 1968, describes the location of the horizontal intrapetrous carotid artery, and is defined by the foramen ovale, the foramen spinosum, the posterior border of the mandibular division of the trigeminal nerve, and the cochlear apex. The posteromedial triangle, first described by Kawase, allows a window into the petrous apex to the posterior fossa. ${ }^{16-19}$ The posteroinferior triangle is defined by the porus trigeminus, the posterior clinoid, and the entrance to the Dorello canal. An incision in this area exposes the petrosphenoidal ligament (Gruber ligament), which forms the roof of the Dorello canal. The anterolateral triangle is defined by the area between the first and second divisions of the trigeminal nerve in their exit in the middle cranial fossa. ${ }^{16-18}$

The cavernous sinus can be divided into four separate quadrants. Lesions involving the anteromedial region are approached via the anteromedial and anterolateral triangles. Because these two triangles are exposed extradurally, in selected cases (such as neurinoma of the mandibular portion of the trigeminal nerve [V2], for example), opening the dura mater might not be necessary in the resection of such a lesion. This concept similarly applies to lesions located in the anterolateral quadrant, approached via the lateral loop and posterolateral triangles. ${ }^{12-21}$

More posterior lesions, involving the posteromedial and posterolateral regions of the cavernous sinus, usually require exposure through the medial, superior, and lateral triangles. These triangles, although possible to open through an extradural route, are typically entered intradurally. Posteromedial lesions without extension lateral to the cavernous carotid artery may also be considered for an endonasal endoscopic approach. ${ }^{17-19}$ Masses confined mainly to the posterolateral quadrant of the region are best approached laterally through the middle fossa in our opinion. Lesions involving more than one of these four areas, such as a mass with extensive posterior cavernous involvement with extension into the posterior fossa, for example, may require a combined approach for adequate exposure. ${ }^{17-19}$

\section{Case 1}

A 56 year-old male was admitted with history of headache and diplopia. A neurological examination showed left
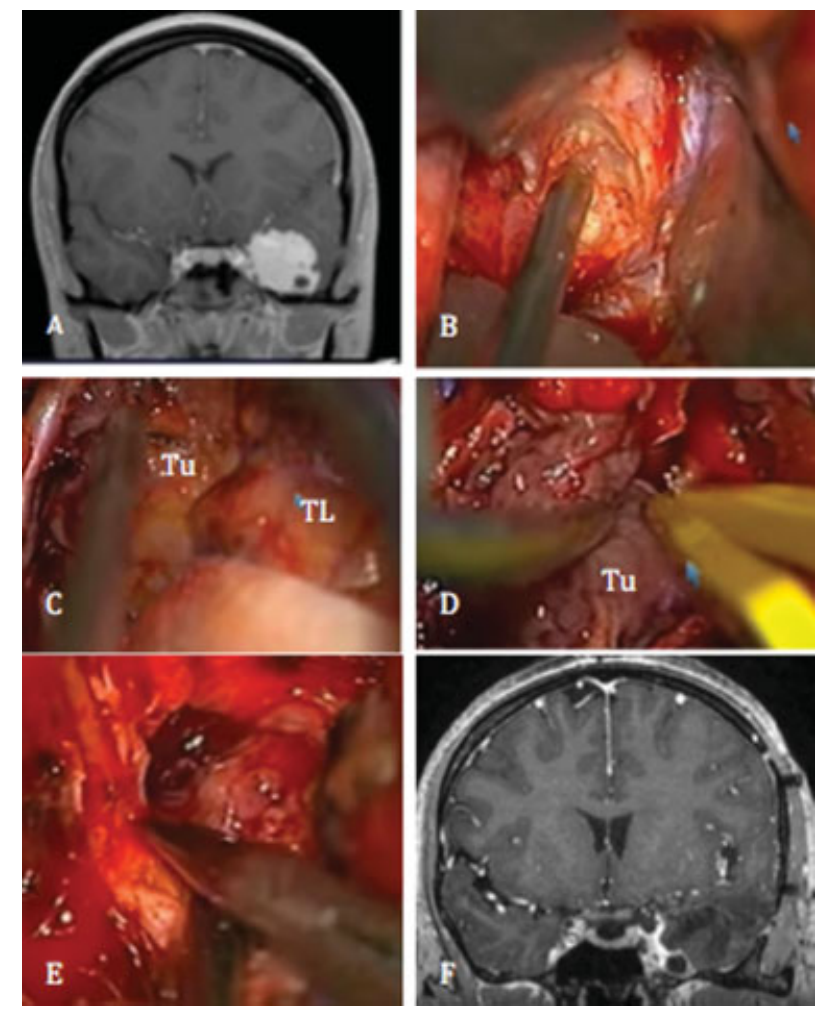

Fig. 4 Example of a case of cavernous sinus meningioma treated by microsurgical extra- and intradural approaches. (A) Preoperative magnetic resonance imaging (MRI) showing a left cavernous sinus extra-axial lesion extending to the medial fossa; (B) extradural approach drilling the anterior clinoid process; $(C)$ intradural dissection of the temporal lobe (TL) and tumor capsule (Tu); (D) dissection of the tumor from the lateral wall of the cavernous sinus; (E) after tumor resection, showing the preservation of the neural and vascular structures; (F) postoperative MRI. 
oculomotor and trochlear palsies. A computed tomography (CT) scan and magnetic resonance imaging (MRI) (- Fig. 4) were performed with left cavernous homogeneous lesion with middle fossae extension and intracavernous carotid artery stenosis. He was submitted to left fronto-temporal craniotomy and middle fossae peeling with subtotal tumor resection through the lateral, antero-lateral and far-lateral triangles. He was discharged ten days after surgery with worse ocular palsy anatomopathologicaly compatible with meningotelial meningioma (World Health Organization [WHO] grade 1 ). Therefore, adjuvant radiation therapy was indicated. After nine months, he had an improvement in the ocular palsy, and an MRI showed no tumor growing rates.

\section{Endoscopic Approaches to the Cavernous Sinus}

Medial lesions may be considered for the endonasal endoscopic approach and lateral lesions by middle fossa. ${ }^{14,19,21-24}$ The introduction of the endoscope in pituitary surgery enabled a wide peripheral vision through a limited surgical channel and an adequate lateral control of the cavernous sinus region. The results attained in the treatment of pituitary adenomas, fistula correction and the development of specific technology to improve hemostasis pushed us to apply endoscopic endonasal surgery to the treatment of cavernous sinus tumors. $^{22,23}$
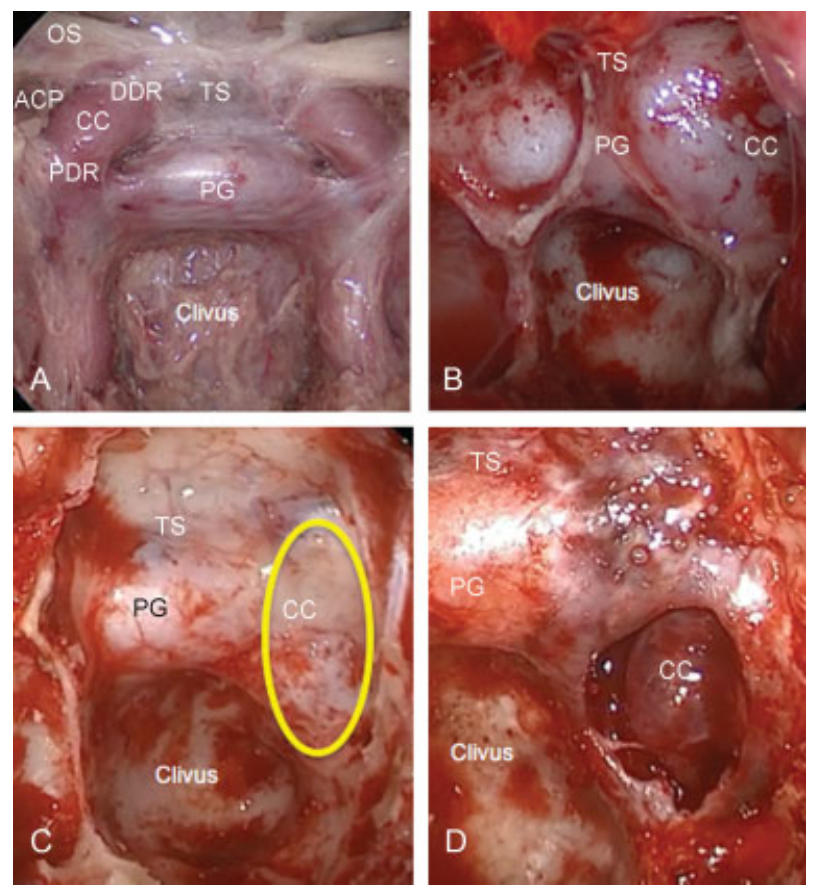

Fig. 5 Endoscopic view of the transsphenoidal and transpterygoid approaches. (A) transsphenoidal approach in a cadaveric specimen; (B) transsphenoidal approach; (C) transpterygoid approach; (D) transpterygoid approach showing the left cavernous sinus after tumor resection. Abbreviations: ACP, anterior clinoid process; CC, cavernous carotid artery; DDR, distal dural ring; OS, optic sheet; PDR, proximal dural ring; PG, pituitary gland impression; TS, tuberculum sellae. Note: the yellow circle shows the position of the cavernous sinus.
Multiple endoscopic endonasal surgical corridors to the cavernous sinus have been described, giving access to the medial and lateral compartments (relative to the position of the intracavernous internal carotid artery). ${ }^{24-26}$ The choice of approach is based on the grade, type and location of the lesions in the cavernous sinus. Lesions confined to the medial and postero-superior compartments are treated by a transsphenoidal transselar transcavernous (TTT) endoscopic approach. When the lesion is located in the lateral or antero-inferior compartments, an endoscopic ethmoid-pterygoid-sphenoidal (EPS) approach is required. ${ }^{22,23}$

The TTT endoscopic approach is initiated using a $0^{\circ}$ rod lens endoscope. The lateralization of the inferior turbinates increases the space for the insertion and manipulation of the instruments. First, a nasoseptal flap is prepared for reconstruction of the skull base defect at the end of the procedure. A posterior nasal septectomy in addition to wide bilateral sphenoidotomies and posterior ethmoidectomies complete the nasal corridor. The anterior wall of the sella is drilled out, exposing the superior and inferior intercavernous sinuses
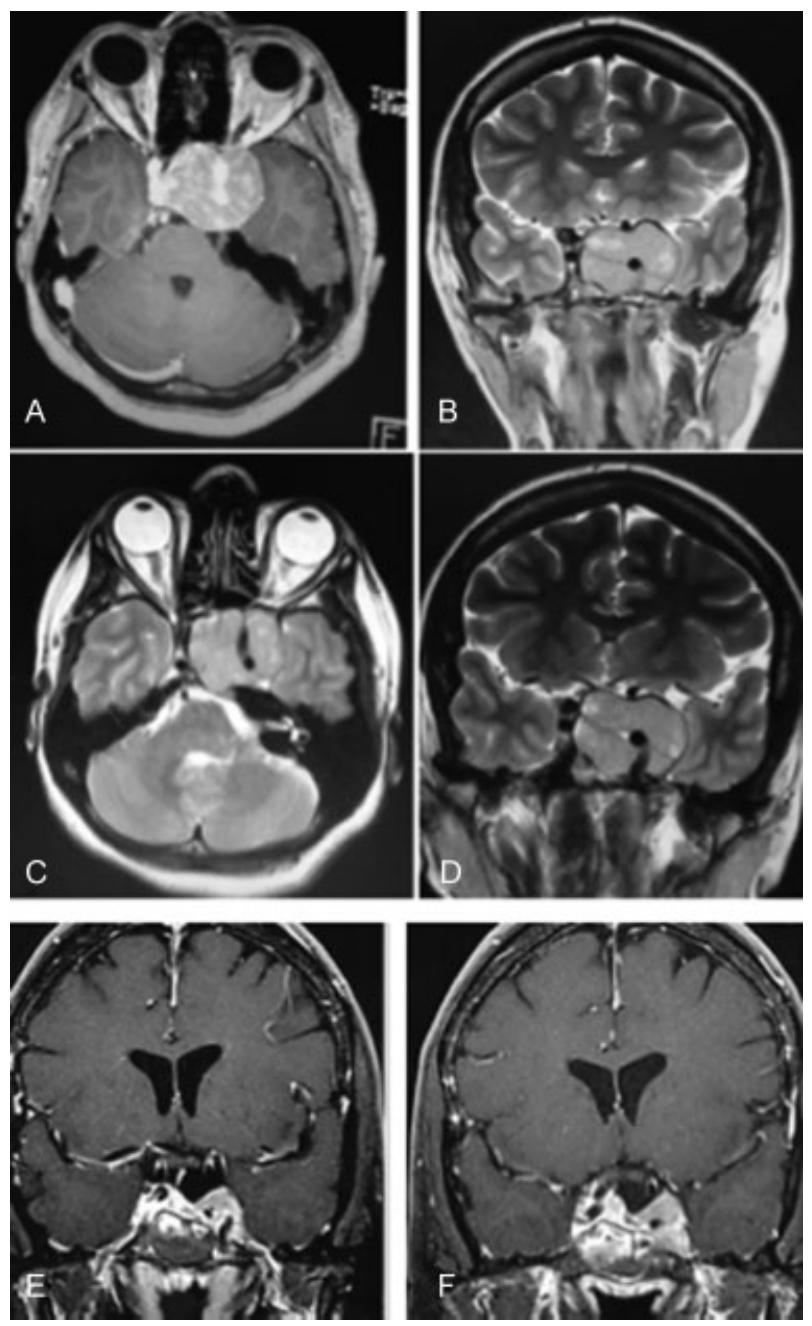

Fig. 6 (A) Axial preoperative T1-enhanced MRI of a pituitary tumor with extension to the left cavernous sinus; (B) coronal preoperative of a T2 MRI; (C) axial T2 MRI; (D) coronal preoperative T2 MRI; (E) axial 6 moths postoperative MRI; (F) axial 6 months postoperative MRI. 
and the cavernous sinus bilaterally. This relatively wide exposure, coupled with an incision of the dura, enables an unencumbered intrasellar dissection. The most common indications for this approach are pituitary tumors extending to the medial compartment of the cavernous sinus (-Fig. 5). ${ }^{22-30}$

The EPS approach enables the frontal view of the cavernous sinus with direct control of the medial and lateral compartments. The procedure starts with an ethmoidectomy with partial resection of the middle and superior turbinates. Then, opening the posterior ethmoidal cells enables the exposure of the anterior wall of sphenoid sinus, the orbital apex and the base of the pterygoid. The anterior wall of the sphenoid sinus is removed, and the sphenopalatine artery is cauterized using a bipolar forceps. At this point, the posterior wall of the maxillary sinus is exposed by a medial maxillectomy in the area of the middle and posterior thirds of the inferior turbinate, opening the pterygomaxillary fossae. After the removal of the posterior wall of the maxillary sinus, the contents of pterygomaxillary and infratemporal fossae are visible. Then, the vidian artery is cauterized, and the base of the pterygoid process and the sphenoidal sinus floor are drilled out. This maneuver enables the visualization of the cavernous sinus and middle cranial fossae. In cases in which lateral inspection is needed, a total maxillectomy may be performed with this approach. Moreover, the procedure comprises a wide contralateral transsphenoidal approach. With the exception of the tumor exclusively located in the lateral portion of the cavernous sinus, dural opening is made in the sellar region, and is progressively enlarged following the lesion from the medial to the lateral portions (- Fig. 5). ${ }^{22-30}$

Closure is performed with fat, fascia lata, nasoseptal flap and dura mater sealants. The external lumbar drain is not used unless an intraoperative high-flow leak of cerebrospinal fluid (CSF) is observed.

\section{Case 2}

A 31 year-old female was admitted at the emergency room with headache, visual disturbances characterized by left temporal hemianopsia, diplopia and strabismus. She had a previous transsphenoidal surgery for the treatment of a pituitary tumor in 2011. Upon neurological examination, she had complete left third nerve palsy and incomplete deficits in the fourth and sixth nerves. An MRI showed a residual pituitary tumor with an extension to the left of the cavernous sinus (-Fig. 6). Hormonal screening showed panhypopituitarism. She was submitted to an extended endoscopic endonasal transsphenoidal transpterygoid approach to the tumor (-Fig. 7). After five days, she was discharged in good health condition, with complete recovery of the fourth and sixth nerve palsies and improvement of third nerve deficit and left temporal hemianopsia. At six months follow-up, she had a complete recovery of the visual disturbances, but an MRI showed a small residual tumor ( - Fig. 6 E and $\mathbf{6 F}$ ). Conservative treatment was indicated with a new MRI in three months.
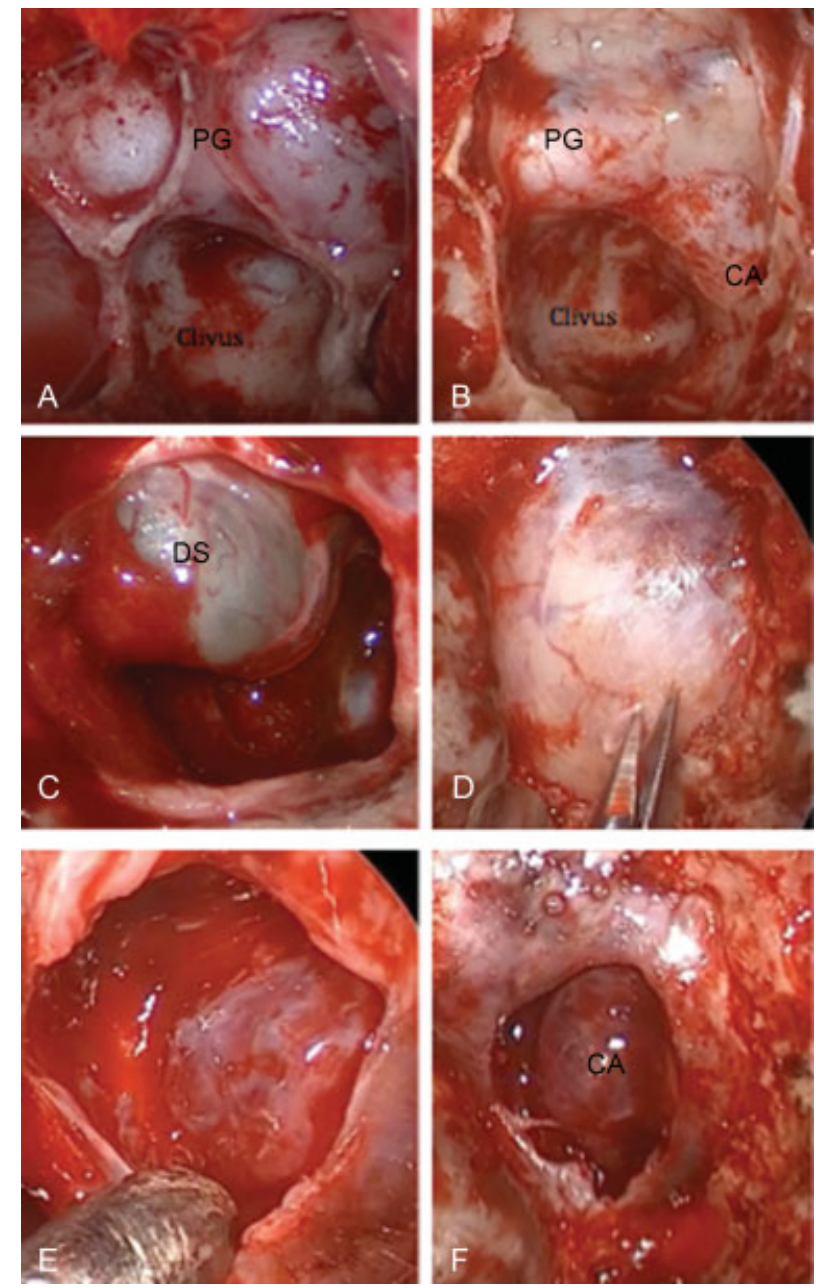

Fig. 7 Endoscopic approach to the tumor in the sellar region extending to left cavernous sinus. (A) Endoscopic transsphenoidal view of the anatomy of the base of the skull; (B) endoscopic transpterygoid view of the lateral left cavernous region and its relationships; (C) view of the sellae after intrasellar tumor resection; (D) opening the dura anteriorly to the cavernous sinus; (E) View into cavernous sinus during tumor resection; $(F)$ view after tumor resection. Abbreviations: CA, carotid artery; DS, diaphragm sella; PG, pituitary gland.

\section{Conclusion}

Cavernous sinus lesions are challenging, with high surgical risks. Extensive microsurgical anatomical knowledge and endoscopic skills are required to choose the best treatment and surgical approach. The microsurgical and endoscopic approaches have specific indications based on the position of the lesion and the skills of the surgeon.

\section{References}

1 Yasuda A, Campero A, Martins C, Rhoton ALJr, de Oliveira E, Ribas GC. Microsurgical anatomy and approaches to the cavernous sinus. Neurosurgery 2005;56(1, Suppl)4-27, discussion 4-27

2 Rhoton AL Jr. The supratentorial cranial space: Microsurgical anatomy and surgical approaches. Neurosurgery 2002;51(Suppl 1): $375-410$ 
3 Sekhar LN, Burgess J, Akin O. Anatomical study of the cavernous sinus emphasizing operative approaches and related vascular and neural reconstruction. Neurosurgery 1987;21(06):806-816

4 Parkinson D. The cavernous sinus, in Dolenc VV (ed): The Cavernous Sinus. New York: Springer-Verlag; 1987, pp 3-29

5 Harris FS, Rhoton AL Jr. Anatomy of the cavernous sinus. A microsurgical study. J Neurosurg 1976;45(02):169-180

6 Glasscock ME III. Exposure of intrapetrous portion of the internal carotid artery, in Hamburger CA, Wersall J(eds): Disorders of the Skull Base Region: Proceedings of the Tenth Nobel Symposium, Stockholm, 1968. Stockholm, Almquist and Wiksel, 1969, pp 135-143.

7 Romero FR, Ramos JG, Chaddad-Neto F, Bethencourt JM, de Oliveira E. Microsurgical anatomy and injuries of the abducens nerve. Arq Neuropsiquiatr 2009;67(01):96-101

8 Tedeschi H, de Oliveira EP, Wen HT, Rhoton AL Jr. Perspectives on the approaches to lesions in and around the cavernous sinus. Oper Tech Neurosurg 2001;4:82-107

9 Umansky F, Valarezo A, Elidan J. The superior wall of the cavernous sinus: a microanatomical study. J Neurosurg 1994;81(06): 914-920

10 Yasuda A, Campero A, Martins C, Rhoton AL Jr, Ribas GC. The medial wall of the cavernous sinus: microsurgical anatomy. Neurosurgery 2004;55(01):179-189, discussion 189-190

11 Sekhar LN, Møller AR. Operative management of tumors involving the cavernous sinus. J Neurosurg 1986;64(06):879-889

12 Alfieri A, Jho HD. Endoscopic endonasal cavernous sinus surgery: an anatomic study. Neurosurgery 2001;48(04):827-836, discussion $836-837$

13 Cusimano MD, Sekhar LN, Sen CN, et al. The results of surgery for benign tumors of the cavernous sinus. Neurosurgery 1995; 37(01):1-9, discussion 9-10

14 Arbolay OL, González JG, González RH, Gálvez YH. Extended endoscopic endonasal approach to the skull base. Minim Invasive Neurosurg 2009;52(03):114-118

15 Cavallo LM, Cappabianca P, Galzio R, Iaconetta G, de Divitiis E, Tschabitscher M. Endoscopic transnasal approach to the cavernous sinus versus transcranial route: anatomic study. Neurosurgery 2005;56(2, Suppl)379-389, discussion 379-389

16 DeMonte F, Smith HK, al-Mefty O. Outcome of aggressive removal of cavernous sinus meningiomas. J Neurosurg 1994;81(02):245-251

17 Isolan GR, Krayenbühl N, de Oliveira E, Al-Mefty O. Microsurgical Anatomy of the Cavernous Sinus: Measurements of the Triangles in and around It. Skull Base 2007;17(06):357-367

18 Isolan G, de Oliveira E, Mattos JP. Microsurgical anatomy of the arterial compartment of the cavernous sinus: analysis of 24 cavernous sinus. Arq Neuropsiquiatr 2005;63(2A):259-264
19 Jho HD, Ha HG. Endoscopic endonasal skull base surgery: Part 2The cavernous sinus. Minim Invasive Neurosurg 2004;47(01): 9-15

20 Eisenberg MB, Al-Mefty O, DeMonte F, Burson GT. Benign nonmeningeal tumors of the cavernous sinus. Neurosurgery 1999; 44(05):949-954, discussion 954-955

21 Frank G, Pasquini E. Endoscopic endonasal cavernous sinus surgery, with special reference to pituitary adenomas. Front Horm Res 2006;34:64-82

22 Kassam AB, Gardner P, Snyderman C, Mintz A, Carrau R. Expanded endonasal approach: fully endoscopic, completely transnasal approach to the middle third of the clivus, petrous bone, middle cranial fossa, and infratemporal fossa. Neurosurg Focus 2005; 19(01):E6

23 Kassam AB, Prevedello DM, Carrau RL, et al. The front door to meckel's cave: an anteromedial corridor via expanded endoscopic endonasal approach- technical considerations and clinical series. Neurosurgery 2009;64(3, Suppl)ons71-ons82, discussion ons82-ons83

24 Zhao B, Wei YK, Li GL, et al. Extended transsphenoidal approach for pituitary adenomas invading the anterior cranial base, cavernous sinus, and clivus: a single-center experience with 126 consecutive cases. J Neurosurg 2010;112(01): 108-117

25 Woodworth GF, Patel KS, Shin B, et al. Surgical outcomes using a medial-to-lateral endonasal endoscopic approach to pituitary adenomas invading the cavernous sinus. J Neurosurg 2014; 120(05):1086-1094

26 Nishioka H, Fukuhara N, Horiguchi K, Yamada S. Aggressive transsphenoidal resection of tumors invading the cavernous sinus in patients with acromegaly: predictive factors, strategies, and outcomes. J Neurosurg 2014;121(03):505-510

27 Ceylan S, Koc K, Anik I. Endoscopic endonasal transsphenoidal approach for pituitary adenomas invading the cavernous sinus. J Neurosurg 2010;112(01):99-107

28 Cappabianca P, Cavallo LM, Esposito F, De Divitiis O, Messina A, De Divitiis E. Extended endoscopic endonasal approach to the midline skull base: the evolving role of transsphenoidal surgery. Adv Tech Stand Neurosurg 2008;33:151-199

29 Inoue T, Rhoton AL Jr, Theele D, Barry ME. Surgical approaches to the cavernous sinus: a microsurgical study. Neurosurgery 1990; 26(06):903-932

30 de Divitiis O, Conti A, Angileri FF, Cardali S, La Torre D, Tschabitscher M. Endoscopic transoral-transclival approach to the brainstem and surrounding cisternal space: anatomic study. Neurosurgery 2004;54(01):125-130, discussion 130 